\title{
Interaction between College English Exploratory Course Construction and Teachers Development
}

\author{
Wei Li \\ Baoshan College of Traditional Chinese Medicine, Baoshan Yunnan, 678000, China
}

Key words: College English, Exploratory course construction, Teacher development interaction.

\begin{abstract}
In recent years, our country began to reform the education work, during the process, college English teaching has been widely concerned. However, college English teachers' professional development encounters obstacles, that is, in the teaching process, problems which are difficult to be solved often appear. This article will analyze the difficulties in the college English teachers' teaching, predicting the new mode of college English education in the future based on the study of the development trend, and finally formulating the idea structure according to the relationship between the teacher and English courses to guarantee that the level of teachers' specialization could be enhanced and then lay a good foundation for the development.
\end{abstract}

\section{Introduction}

In the case of study of the present situation of English major curriculum at home and abroad, it can be found that most of the English curriculum structures are relatively concentrated with in-depth research on the course system, teaching mode and teaching effect. However, to a certain extent, the development of teachers and teachers' professional quality are ignored. The advantages of the curriculum reform can not be played. Besides, the research made by state on college English teacher development and curriculum system construction is rare. Therefore, the related education department must attach much importance to the connection between the development of college English teachers' quality and development of the curriculum system construction to effectively improve college English teaching quality.

\section{The relation between college English exploratory course construction and teachers' quality development}

In the process of college English education and teaching implementation, there is a direct link between construction of exploratory course and the development of teachers' quality. If education management personnel were to promote the interaction between the two, they must first understand the relationship between all structures in order to improve the work efficiency. There is a good interactive relationship between college English exploratory course and teachers' professional quality mainly because the construction of the exploratory course is a way for teachers to learn professional knowledge. Teachers can develop their own professional quality through exploratory course platform and develop new projects. For the construction of the exploratory course, the development of teachers' professional quality can promote the efficiency of construction, strengthen the construction intensity and introduce the construction innovation model thus lay a good foundation for its development.

The curriculum concept refers to understandings and views on general structure of the course, including: concept, establishment, implementation and evaluation on curriculum, etc. In this process, 
people's understanding of course will be affected by history and culture as well as all kinds of environmental factors, teachers' personal teaching experience, values, etc.

In the 20th century, relevant American experts took curriculum as pilot project and effectively carried out a series of experiments, clearly put forward the viewpoint that teacher is the curriculum. On the experts' opinion, the teacher is an important part of curriculum who can both create curriculum and be the body of the curriculum. Teachers' moral quality, teaching experience, the degree of specialization, practical ability and so on are part of the curriculum. The experts criticized the traditional curriculum theory and pointed out the mistakes teachers make during teaching. Later, a foreign expert and scholar during practice study time put forward several ways of curriculum construction, clearly pointing out that teachers, students and subject content are mutually coordinated and balanced, thus on the basis of this interaction, a relatively perfect curriculum system can be formed.

Many experts and scholars abroad advocate that during the process of teachers' construction of curriculum, they should attach importance to the introduction of real life and discuss with students together about curriculum construction methods. On the basis of constantly setting curriculum situation, experts and scholars require teachers to raise their own professional quality to reconstruct the curriculum concept, to play teachers' role in curriculum construction and to lay a good foundation for the development of curriculum construction.

\section{The development situation of college English teachers}

Since China's reform and opening up, teachers' professional development has become a topic which has caused many people's attention. The main reason is that teachers' professional development is closely related to students' learning. At present, under the influence of education reform, teachers begin to pay attention to their own professional development and constantly reflect on their teaching situation, developing themselves together with students. At the same time, college English teachers' cognition begins to have diversify progress combined with social culture, the way of cooperation and the classroom problem analysis. All these are helpful to improve the efficiency of teachers' professional development.

Though the trend during the process of our country's research on college English teachers' professional development and curriculum construction is considerable, there still exists the following problems: lack of perfect information demonstration, less contact with classroom teaching, teachers' demand research not clear, relationship between teachers and researchers inequal. Especially in the process of college English teachers' development, though targeted research systems are formulated, many of them are study of college English teachers' whole quality and challenges, etc. without clearing out college English teachers' subject system. Besides, there are few study on vocational moral quality. All these lead to a result that, in the teaching process, the problem such as college English teachers often carry out teaching blindly often appears, teachers can not effectively perform work according to their own teaching ability, this has adverse effects on the development of college English teachers.For the bottlenecks college English teachers meet during the development, although experts have studied the theory, it lacks system research demonstration. In the process of research, reasonable measures for college English teachers' professional development can't be formulated, leading adverse effects on the college English professional education teaching in China[1].

\section{The current situation and trend of development of college English education}

College English education is one of the teaching programs our country has paid more attention to, especially in recent years, our country has conducted a series of research to it. However, at present our country takes reform on the university entrance exam, compressing the English credits, thus college English could no longer be taken seriously, not able to cause students' attention. During the process of development, college English faces the survival crisis. How to solve such problems has become the key work in the college English education. After research on college English positioning and survival 
factors, experts put forward several point of view on the course structure change, repositioning college English, then creating development chance for academic subject[2].

In addition to effective subject positioning, relevant researchers also should attach great importance to the college English curriculum reform and construction work. It must require that university schools should take English as a compulsory course, or set it as a minor course, innovating structure system to make it a multi-level content. At this time, the following contents should be paid attention to : How college English teachers construct curriculum system in daily work, effectively setting curriculum goals, perfecting the course content, putting forward a more reasonable way of evaluation etc. Second, how college English teachers experience the teaching connotation in the process of teaching English, setting up dynamic teaching process etc. Under this background, the construction of the exploratory course can effectively enhance the efficiency of college English teaching reform so that teachers can better engage themselves into curriculum reform work, and then the speed of the development of university teachers can be improved[3].

\section{Interaction research between the construction of college English exploratory course and the development of teachers}

\section{The connotation and application of narrative research}

Narrative research is a more advanced way of research which takes teachers as the main body of the research, taking teaching experience and phenomenon as the research objectives, taking field work, the results of the investigation, daily life record, interview content and the content of letters as the research resources, story as the research carrier. It is a research which rebuilds the meaning of experience to promote good development of the society on the basis of full understanding. Since the 1980s, the English research work began to abandon the traditional ways of working and introduced a scientific research model--people called it the mainstream research paradigm. The narrative JiaoJiu got the attention from various domestic and foreign professions, especially experts in English education in our country. They not only conducted series of investigations, but also put forward two basic form of narrative research in English: First, the reflection on the current status, abandoning the traditional teaching research pattern. Second, using narrative research to record the experience and development of the teachers[4].

In 2005, experts used the method such as narrative research to study the college English teachers in curriculum reform. Analyzing the results of the study, it is known that when teachers are under learning and development, they can coordinate activities of each link of the course. Under the basis of construction of exploratory course, they improved their development efficiency and got some achievements. In 2009, experts research shows that teachers when enhancing their professional ability, they could use the way of narrative study and teaching case to perform all kinds of teaching practice, and further explore the true meaning of education teaching, having deep understanding of education work. Through the application of the narrative way of research, it is found that the teacher must pay attention to the cognition of education, use the method of narrative research to study the exploratory course construction and promote the development of education [5].

\section{Ideas on the implementation framework}

On the basis of in reference to the above research, I carried out research on the exploratory course construction on 20 teachers of the college English department and took them as the objective of the research, combined with the way of a narrative and inquiry way to implement, with data analysis, research is mainly for the following three questions: after construction of the exploratory course, how college English teachers' professional developed, the change of college English teachers' curriculum, how the interaction mechanism between the development of college English teachers and exploratory course construction established.

The study is carried out according to the three questions, five steps, embodied in the following:

Level one: theory framework 
1.Combing the relation between teachers' professional development and the course construction according to searching and analyzing related documents, filling out the data from the investigation into the scale. Considering things from the angle of teachers or related groups according to the research on teachers' faith, reflection and study, further highlighting the special problems existing in college English teaching--problems at this time should be related to the course construction. Constantly retrieving college English teachers' professional development and curriculum and other related documents to clear the relationship between the teaching methods and evaluation work, to some extent, reviewing the literature to ensure that scientific and reasonable investigation scales could be formulated.

2. Questionnaire and interview work, to a certain extent, studying the present situation of the college English teachers' professional development and the course construction. Before the construction of college English exploratory course, questionnaire and interview work on teachers should be done. After finishing all this kind of work, the relevant management personnel should take back the questionnaire and do a series of statistical, while recordings can be appropriate converted into words. Then, based on the analysis of teachers' beliefs and all kinds of type of work, analyzing the current situation of the development of teachers.

Level two: assuming English course

3. Focusing on the time pattern of the construction of the curriculum. Using the narrative way to record the whole process of curriculum construction. First of all, analyzing teachers' classroom teaching situation, the daily teaching record and all links of teaching. In this way the teachers' curriculum establishment and classroom teaching can be effectively embodied.

4. During the process of course construction, relevant management personnel should clear the interaction between the teacher development and curriculum construction, analyzing various data to reveal the mechanism of teacher development and curriculum construction under the basis of observing the classroom teaching behavior and recording the activity details,recording the process of university teachers' curriculum construction and curriculum ideas according to the facts. Besides, they should deeply explore the interaction mechanism between the university teachers' professional development and the curriculum construction.

Level three: College English curriculum system dynamic architecture

5. Relevant personnel should reflect on the construction of the course and fully understand the concept of college English education, reconstructing the curriculum system--the curriculum system here should be dynamic. Respecting the combination of theory with practice, arranging college English teachers to participate in the research work, fully reflecting and summarizing research work, playing the advantage of college English teachers' professional development in the field of education, fully studying the feasibility of teacher professional development narrative research. At the same time, they should pay attention to the exposition of the relation between teachers and college English curriculum construction, teachers with college English major students, teachers and themselves, teachers and other teachers etc. during the process of reflecting and summarizing the course construction work, clearing the value of teachers in college English teaching. They should fully discuss the interactive mechanism between college English curriculum construction and teachers' development, setting English teaching goals, constructing dynamic curriculum structure so as to facilitate the construction of college English course and supplying which to other college English teachers' reference.

\section{The work advantage and significance}

During the process of implementing the above framework ideas, studying according to the theory curriculum system construction and college English teachers' professional war can make university teachers able to raise their professional development efficiency according to the construction of the course and get the teaching experience and enlightenment by education reform. At the same time, the use of the way of narrative research can effectively reveal college English teachers' defects in the teaching to promote teachers' teaching activities to coordinate with daily life, and to some extent 
providing professional development way for teachers. Trying new teaching methods daringly, introducing educational technology, enhancing the teaching ability through the exploratory course construction, laying a good foundation for its development.

\section{Conclusion}

In the process of interactive mechanism research between college English exploratory course construction and teacher development, relevant researchers should pay more attention to the role of teachers in curriculum construction and build a good assumed structure. Besides, they should also use teachers' practice analysis in English teaching to put forward the development trend of teachers to make the accelerating relation between teacher development and curriculum construction able to be embodied, using advanced narrative research to make a good guarantee for its development.

\section{References}

[1] Li Xiaolan, College English development course construction research - Taking Taizhou Institute of Science and Technology--Institute of Technology of Nanjing as Example, Crazy English (teachers), 2012 (4) : 62-65.

[2] Hu Ming Yong, Thinking on construction of college English exploratory course, Journal of Taiyuan City Vocational and Technical College, 2011 (1) : 167-168.

[3] Yu Dewei, Gao Pang, Dai Gongwei etc, College English exploratory course construction research , Chinese journal of education (foreign language teaching), 2015 (1) : 113-114.

[4] Zhang Zhi Hong,Thinking on construction of college English exploratory course, 2014 (15) : 180-180.

[5] $\mathrm{Xu}$ Wei, College English exploratory course study under task-based teaching mode--taking Anshan Normal University as example, Journal of campus English (late), 2016 (2) : 31-31, 32. 